\title{
As várias faces do plágio entre estudantes do ensino superior: um estudo de caso
}

\author{
Madalena Ramos ${ }^{1}$ \\ ORCID: 0000-0002-3117-4498 \\ César Morais ${ }^{2}$ \\ ORCID: 0000-0001-6741-0037
}

\section{Resumo}

O olhar sociológico sobre o plágio entre alunos do ensino superior nas últimas décadas tem produzido progressos teóricos e metodológicos que permitem problematizar e monitorizar esse antigo e persistente fenômeno, considerando seus contornos contemporâneos. Este artigo, resultante de um projeto de investigação, sistematiza alguns desses avanços por forma a analisar criticamente as percepções sobre várias formas de plágio entre estudantes no ano letivo de 2015/2016 numa instituição de ensino superior portuguesa, aferindo (des)continuidades entre vários ciclos de estudo e controlando o efeito das variáveis sexo, idade, área de estudos e conhecimento do código acadêmico em vigor nessa instituição. Os dados em análise resultam de uma inquirição por questionário e permitem verificar que as percepções dos estudantes sobre o que constitui plágio divergem, especialmente em relação a algumas formas de plagiar, ainda que ganhem acuidade ao longo do percurso acadêmico. Por outro lado, os estudantes dos diferentes ciclos destacam o papel do conhecimento e do acompanhamento dos professores na prevenção dessa prática antiética. 0 impacto positivo da socialização acadêmica nessas percepções atesta a importância de uma pedagogia voltada para a honestidade e para a escrita intertextual, clamada pelos próprios estudantes, mas frequentemente secundarizada nas políticas de prevenção e nos currículos acadêmicos das instituições de ensino superior.

\section{Palavras-chave}

Plágio - Percepções - Motivações - Estudantes do ensino superior.

1- Iscte-Instituto Universitário de Lisboa, CIES_Iscte, Lisboa, Portugal. Contato: madalena.ramos@iscte-iul.pt

2- Centro Interdisciplinar de Ciências Sociais (CICS.NOVA), Faculdade de Ciências Sociais e Humanas (NOVA FCSH), Universidade Nova de Lisboa, Lisboa, Portugal. Contato: calm@fcsh.unl.pt 


\section{The multiple faces of plagiarism among higher education students: a case study}

\section{Abstract}

The sociological view on plagiarism among higher education students has produced in recent decades theoretical and methodological advances that enable to problematize and monitor this old and persistent phenomenon, considering its contemporary aspects. This article, resulting from a research project, systematises some of those advances in order to critically analyse the perceptions about various forms of plagiarism among students in the 2015/2016 academic year at a Portuguese higher education institution, assessing (dis) continuities between various levels of study and controlling for the effect of the variables sex, age, area of study and knowledge of the academic code of conduct in use at that institution. The data under analysis results from a questionnaire survey and demonstrates that students' perceptions of what constitutes plagiarism diverge, especially in relation to some forms of plagiarism, even though they gain incisiveness throughout the academic career. On the other hand, students from different levels of study highlight the role of knowledge and teachers' guidance in preventing this unethical practice. The positive impact of academic socialisation on these perceptions demonstrates the importance of a pedagogy that addresses honesty and intertextual writing, demanded by the students themselves, but often overlooked in the prevention policies and academic curricula of higher education institutions.

\section{Keywords}

Plagiarism - Perceptions - Motivations - Higher education students.

\section{Introdução}

Desde o início deste século, o fenômeno do plágio entre alunos do ensino superior tem suscitado um crescente interesse na esfera científica e acadêmica. Ao longo desse período, várias investigações em diversas áreas científicas analisaram a relação dos estudantes com o plágio, procurando mapear quem plagia, qual a incidência das suas diferentes formas, quais suas motivações e seus inibidores (PARK, 2003). Os resultados obtidos levaram a mudanças na forma como o plágio é perspectivado e mensurado, contribuindo assim para uma reflexão mais informada sobre as políticas institucionais que visam prevenir, vigiar e sancionar essa prática.

Destacam-se duas viragens na problematização do plágio com impacto assinalável a nível conceptual e político. Por um lado, reconheceu-se progressivamente sua pluralidade, decompondo-se o plágio em diversas formas de plagiar e assumindo-se a dificuldade em traçar claramente, excetuando, nos casos extremos, as fronteiras entre elas (CHILDERS; 
BRUTON, 2015). Por outro, o plágio passou a ser perspectivado tanto como um problema de (i)moralidade como de (des)conhecimento sobre a cultura acadêmica e o processo de escrita cientifica intertextual (ADAM, 2016) ${ }^{3}$.

Este artigo inscreve-se nesta linha de investigação e tem por objetivo geral avaliar as percepções sobre plágio, incluindo o autoplágio e a compra de trabalhos entre estudantes em cursos de primeiro, segundo e terceiro ciclo de uma instituição pública portuguesa de ensino universitário ${ }^{4}$. Trata-se de um estudo de caso que promove uma análise comparativa entre ciclos de ensino, controlando a influência de fatores comumente apontados na literatura como diferenciadores dessas práticas e percepções, designadamente, sexo, idade, conhecimento do código acadêmico e área de estudo. Pretende-se averiguar se os estudantes i) consideram essas práticas fraudulentas; ii) qual a gravidade que lhes atribuem; e iii) que fatores, no seu entender, as motivam.

\section{O plágio entre alunos do ensino superior: (algumas) lições da literatura}

Dificilmente existe consenso entre os resultados dos estudos que procuraram mensurar a incidência das várias formas de plagiar entre alunos do ensino superior (KAPOSI; DELL, 2012). Uma dissonância que se explica, em grande medida, por diferentes formas de operacionalizar e mensurar o plágio, mas também pela influência dos distintos contextos acadêmicos e das desiguais características pessoais dos estudantes.

Apesar de o conceito de plágio não ter definição universalmente aceita, existem pontos comuns nas conceitualizações usualmente avançadas (SUTHERLAND-SMITH, 2008), nomeadamente, a correta declaração da(s) autoria(s) e da originalidade dos textos, assim como a creditação das fontes citadas de acordo com as normas aplicáveis, sendo geralmente considerada irrelevante a intencionalidade do plagiador. Esses pontos de ancoragem conceitual permitem delimitar várias formas de plagiar que, não obstante assumirem diversas nomenclaturas na literatura e poderem ser ainda decompostas em subtipos consoante seu nível de complexidade (BRETAG; MAHMUD, 2009), são geralmente chamadas de: i) plágio verbatim ou palavra por palavra, em que qualquer elemento de um autor (e.g. palavras, argumentos, ideias, figuras) é citado diretamente, mas não creditado; ii) plágio patchwriting ou mosaico, que deriva da reutilização de elementos de outros autores apenas com pequenas alterações e sem referir essas fontes; iii) autoplágio, ou seja, a apresentação, enquanto novo e original, de um trabalho já entregue em momento anterior

\footnotetext{
3- A intertextualidade da escrita científica remete para a forma como, nessa esfera, os novos textos são elaborados tendo por referência os que já existem. Trata-se de um processo de escrita cumulativo que tem tanto de original como de interpretativo e que deve observar um conjunto de princípios e normas para que não incorra em situações de plágio (KAPOSI; DELL, 2012).

4- Portugal integra o conjunto de 48 países europeus que atualmente se inscrevem no Espaço Europeu de Ensino Superior (EEES). Neste espaço, os sistemas de ensino superior nacionais organizam as graduações que atribuem em três ciclos de ensino: o primeiro ciclo, ou licenciatura, é 0 primeiro grau da hierarquia acadêmica e tem duração mínima de três anos; o segundo ciclo, ou mestrado, pressupõe dois novos anos de formação após a licenciatura (existem também cursos de "mestrado integrado", que implicam uma sucessão obrigatória destes dois primeiros ciclos num período formativo que totaliza cinco anos); e o terceiro ciclo, ou doutoramento, apenas acessível a mestres, com duração mínima de quatro anos. 0 sistema de ensino superior no Brasil encontra-se organizado de forma distinta, mas comparável, sendo que os licenciados no EEES correspondem aos graduados em espaço brasileiro, onde se incluem bacharelados, licenciaturas e graduações tecnológicas; enquanto os mestres e os doutores na EEES são equiparáveis aos pós-graduados em terreno brasileiro, que, além de mestrado e doutorado, também engloba as especializações e os MBA.
} 
ou partes extensas de trabalhos prévios sem adição significativa de novos materiais; e iv) compra de um trabalho ou sua apropriação - indevida ou autorizada -, mesmo que este não tenha sido publicado ou avaliado antes. Contudo, excetuando as manifestações extremas dessas práticas, nem sempre suas fronteiras se afiguram inequívocas, conforme sucede quando citações diretas ou indiretas se revelam incorretas ou abusivas, mesmo quando creditadas corretamente. Ademais, os próprios conceitos de autoria e originalidade tendem a ancorar-se numa visão romântica de autor que vem se revelando pouco adequada à atual emergência de espaços de escrita colaborativos e de novas formas de cocriação anônima de textos na arena virtual (SUTHERLAND-SMITH, 2016).

Considerar irrelevante a intencionalidade com que o plágio é cometido permitiu estilhaçar o monopólio da moralidade como enquadramento desse fenômeno. Se até o início deste século a maior parte das investigações assumia que plagiar configurava apenas um comportamento intencional de ludíbrio, atualmente o plágio surge também enquadrado no âmbito dos processos de ensino-aprendizagem de competências para a intertextualidade científica (ADAM, 2016; HUSAIN; SHAKER; MAHFOODH, 2017). Com efeito, nem todos os que acedem ao ensino superior são "acadêmicos-em-espera" (KAPOSI; DELL, 2012), ou seja, nem todos os estudantes possuem uma noção clara do que é a ética acadêmica ou de quais são as normas em vigor nesse contexto e, portanto, parte dos casos de plágio resulta apenas de desconhecimento ou falta de proficiência em relação às convenções em vigor. Essa evolução traduziu-se numa maior preocupação das investigações em averiguar o que os alunos sabem sobre plágio ou acerca das normas acadêmicas que os rodeiam (ADAM, 2016), tendo-se verificado que estes revelam dificuldade em circunscrever esse fenômeno e suas manifestações (CHILDERS; BRUTON, 2016), construir corretamente paráfrases, metáfrases e sumários (HUTCHINGS, 2014), referenciar de forma adequada (GULLIFER; TYSON, 2010), gerir a diversidade e complexidade das referências bibliográficas (POWER, 2009) e que nem sempre conhecem os códigos e os regulamentos institucionais nesse âmbito (GULLIFER; TYSON, 2010).

Convém assinalar o papel particularmente importante que os professores do ensino superior assumem no que concerne às aprendizagens necessárias para evitar o plágio, porém, no seio deste grupo profissional, também se verificam contradições e hesitações diante desse fenômeno, que obstaculizam sobremaneira a promoção da ética acadêmica enquanto prática pedagógica. Com efeito, mesmo que os professores assumam o plágio como comportamento antiético e condenável (DIAS; EISENBERG, 2015), nem todos o definem da mesma maneira ou traçam fronteiras idênticas para suas diversas formas (GOTTARDELLO; PÀMIES; VALVERDE, 2017). Também não surgem unívocos os caminhos a trilhar pelos docentes para promover uma construção autoral isenta de plágio ou de outras práticas incorretas por parte dos seus alunos (DIAS; EISENBERG, 2015), pois, mesmo sendo desejável que a promoção da ética acadêmica se assuma como parte da competência profissional dos docentes (RIOS, 2009), não se afigura claro que todos a possuam, nem tampouco que a cultivem de forma igual. Note-se também que a identificação de situações de plágio - tarefa geralmente atribuída aos professores - beneficiou-se com os desenvolvimentos tecnológicos recentes nessa área, contudo, essa vigilância mais estreita per se afigura-se insuficiente para evitar casos de plágio entre estudantes, especialmente 
quando estes não dispõem de orientação e acompanhamento ao longo do seu percurso estudantil, "principalmente para ajudá-los a encontrar respostas a questões [...] sem serem apenas reprodutores de estudos já realizados” (PEZUK et al., 2020, p. 18).

A difícil contenção do conceito de plágio e das suas possíveis manifestações refletese na pluralidade dos indicadores mobilizados para mensurar sua incidência, aspecto que contribui sobremaneira para a referida descontinuidade dos resultados obtidos (CHILDERS; BRUTON, 2016). Assim, mesmo que a maioria das investigações recorra a inquirições por questionário e considere diversas manifestações de plágio, poucas avaliam os mesmos tipos ou niveis de complexidade. Essas mensurações baseiam-se sobretudo nas declarações dos estudantes inquiridos sobre suas práticas, raramente avaliando estas últimas diretamente (WALKER, 2010). Por outro lado, dado que também entre alunos do ensino superior tende a não existir univocidade quanto ao que constitui plágio e as suas possíveis formas (POWER, 2009), os questionamentos de síntese (e.g. já cometeu plágio?) têm sido progressivamente substituídos por situações ou cenários que descrevem formas concretas de plagiar (e.g. já submeteu um trabalho sem ter colocado as referências bibliográficas em que se apoiou?), sendo ainda usual verificar se essas situações são efetivamente consideradas como plágio.

Mesmo que várias formas de plágio entre alunos do ensino superior se afirmem transversais entre países, instituições de ensino e cursos (ECKSTEIN, 2003), o contexto acadêmico em que se inserem influi sobremaneira nas suas práticas e percepções (MCCABE; TREVIÑO, 1997). O significado do plágio se constrói e se legitima socialmente (PARK, 2003), portanto, mesmo num cenário progressivamente globalizado como o do ensino superior, sobressaem distintas interpretações e posicionamentos relativamente a esse fenômeno entre academias e áreas de estudos (MCCABE; TREVIÑO; BUTTERFIELD, 2002). Afırma-se determinante, por exemplo, a existência de códigos de ética ou similares na redução da incidência das várias formas de plagiar (MCCABE; TREVIÑO, 1997). Não se trata somente da influência de uma "cultura de pares, que tanto pode inibir como legitimar a fraude” (PEIXOTO, 2019, p. 76), mas também de aspectos culturais e sociais mais amplos (HECKLER; FORDE, 2014) que, com maior ou menor notoriedade, introduzem particularidades na relação dos alunos com o plágio consoante o país (GLENDINNING, 2014) ou região do globo (ISON, 2018) em que estudam.

As características individuais dos estudantes do ensino superior, nomeadamente, mas não exclusivamente, seu sexo, idade e ano de curso, também contribuem para explicar porque uns plagiam mais do que outros. Acumulam-se evidências de que os homens revelam maior propensão para plagiar do que as mulheres (PARK, 2003), os mais jovens tendem a recorrer mais frequentemente ao plágio (BRIMBLE, 2016), assim como os calouros (MACDONALD; CARROLL, 2006). São raras as análises que tenham observado a influência do nível de estudos nas práticas ou percepções sobre plágio, no entanto essa relação não se afigura despicienda se considerarmos que a idade e o ano de curso são fatores influentes, pelo menos em relação às práticas.

Os diversos fatores que os alunos do ensino superior julgam que motivam o plágio podem ser agrupados em grandes categorias. Desde logo, motivações relacionadas com: i) falta de ética, o que remete para situações de plágio intencional relacionadas com atitudes e valores pessoais não compatíveis com a honestidade acadêmica (PARK, 2003), como 
considerar o plágio como um crime sem vítimas e, portanto, sem gravidade (BRIMBLE, 2016), ou julgar que este compensa em relação a um cálculo utilitarista entre o esforço a realizar e a classificação a obter (WOESSNER, 2004); ii) lacunas em aprendizagens, nomeadamente sobre o plágio ou as normas e regras relativas à prática (PARK, 2003); iii) currículos dos cursos, já que os alunos consideram que a motivação para plagiar também pode advir da falta de interesse pelo conteúdo curricular a ser tratado, da repetição de temas de trabalho em diferentes unidades curriculares ou do pouco acompanhamento docente (BRIMBLE, 2016); iv) a influência dos pares, uma vez que os estudantes apontaram ser mais provável cometer plágio em contextos acadêmicos onde sua prevalência é elevada (MCCABE; TREVIÑO, 1997), - tratando-se de uma "neutralização" dessa prática fraudulenta, justificada pelo comportamento dos outros, permitindo assim mitigar eventuais sentimentos de culpa ou de embaraço (RETTINGER; KRAMER, 2008); v) vigilância e sanções minimalistas surgem também apontadas como incentivo para plagiar (PARK, 2003; WOESSNER, 2004); e, por último, vi) o atual estilo de vida, seja porque os estudantes alegam dispor de pouco tempo para completar os trabalhos acadêmicos de forma honesta, atendendo aos seus múltiplos compromissos exteriores ao ensino (BRIMBLE, 2016), ou porque a elevada pressão para obter notas altas incentiva uma mentalidade de "sucesso a todo o custo" (BEASLEY, 2014).

\section{O plágio entre alunos do ensino superior em Portugal}

Em Portugal, contexto em que se insere esta investigação, apenas decorreram três investigações que observaram a relação dos alunos do ensino superior com o plágio; todas datam da primeira metade desta década, recorreram a inquirições por questionário, diretas ou indiretas, e a procedimentos amostrais não probabilísticos.

Apenas o primeiro desses estudos procurou, tal como aqui se fará, averiguar a evolução dessa relação de acordo com o ciclo de estudos, ainda que a partir de uma amostra que incluía estudantes de diversas proveniências institucionais $(n=5.403)$ e procurando, sobretudo, realizar um levantamento dos "diversos comportamentos e condutas desviantes por parte de estudantes do ensino superior” (TEIXEIRA, 2011, p. 1), enquanto esta análise se centra essencialmente nas suas percepções. Essas percepções foram alvo de escrutínio em Almeida et al. (2015, 2016), englobando estudantes de cursos de primeiro ciclo ou similares (incluindo mestrado integrado), em diversas áreas de estudos e na globalidade do ensino superior português, quer universitário, quer politécnico, tanto público como privado $(n=7.292)$. Além dos resultados globais, este projeto produziu também uma análise detalhada de uma subamostra $(n=2.362)$ composta unicamente por alunos de licenciaturas em economia e administração (GAMA et al., 2013a, 2013b). Esta investigação versou sobre a fraude acadêmica, e não apenas sobre o plágio, portanto as especificidades dessa prática ou de quem a comete não foram alvo de aprofundamento. Por outro lado, a incidência de fraudes foi mensurada de forma projetiva, ou seja, questionando acerca da frequência com que os outros o fazem ou da predisposição para fazê-lo no futuro, uma metodologia que se distingue deste e dos demais estudos. A investigação mais recente resulta de um projeto internacional coordenado em território português por Irene Glendinning (2014), mas mais dedicado a avaliar políticas e práticas institucionais relacionadas ao plágio do 
que comportamentos e atitudes dos estudantes, tendo analisado estes últimos por recurso a uma amostra de reduzida dimensão $(n=189)$, que englobava alunos de primeiro e segundo ciclo em vários cursos e instituições de ensino.

Essas investigações, não obstante sua qualidade intrínseca, apresentaram objetivos e mobilizaram indicadores díspares entre si e, também, dificilmente compagináveis com esta análise, o que inviabiliza quaisquer comparações diretas. Existem, porém, paralelismos entre esses estudos que serão cotejados cumulativamente nesta análise, visando relativizar sua circunscrição institucional.

\section{Metodologia}

0 método de coleta de dados foi a inquirição por questionário, uma metodologia quantitativa particularmente frequente nas pesquisas nesta área de estudos e, especificamente, nas desenvolvidas em contexto português. 0 questionário aplicado considera exemplos de investigações anteriores, procurando, porém, acolher os debates metodológicos contemporâneos antes referidos, isto é, além de incluir indicadores de síntese sobre a incidência do plágio, também mobiliza outros que reportam a descrições de formas específicas dessa prática, como o plágio palavra por palavra ou o autoplágio, visando avaliar sua incidência e seu reconhecimento enquanto plágio. Esta inquirição integra um projeto de investigação coordenado pelos autores e decorreu numa única instituição universitária pública portuguesa, tendo sido apoiada pelo Conselho Pedagógico dessa instituição no âmbito de um dos seus eixos estratégicos: a promoção da integridade acadêmica ${ }^{5}$.

Todos os estudantes no ano letivo de 2015/2016 da instituição investigada foram convidados, por correio eletrônico, a participar de uma inquirição sobre plágio, enviando suas respostas por meio de uma plataforma on-line, disponível entre fevereiro e março de 2016, que salvaguardava o anonimato dos participantes. Responderam 649 alunos dos diversos cursos e ciclos de ensino das graduações, o que representa uma amostra não probabilística de cerca de 8 por cento dos estudantes no primeiro ciclo $(N=4.254 ; n=328)$, 7 por cento no segundo $(N=3.649 ; n=255)$ e 9 por cento no terceiro $(N=752 ; n=66)$ nesse ano letivo.

Realizou-se a análise comparando as percepções sobre plágio dos estudantes de primeiro, segundo e terceiro ciclos, procurando também aferir se estas se distinguem de acordo com fatores contextuais e características individuais. Quanto aos primeiros, uma vez que todos os inquiridos estudam na mesma instituição, recorreremos apenas à distinção por áreas de estudo; quanto às segundas, mobilizaremos sexo, idade e conhecimento da existência de regulamentação para situações de plágio. A utilização desta última variável procura testar se o desconhecimento da existência de códigos e regulamentos sobre plágio influencia as percepções dos estudantes (Tabela 1).

5 - 0 questionário aplicado teve como ponto de partida, mediante consentimento, o questionário desenvolvido no âmbito do estudo "Plagiarism", coordenado por Harko Verhagen na Universidade de Estocolmo (RAZERA et al., 2010), tendo, todavia, sofrido alterações profundas, 0 que resultou numa versão bastante diferente. 
Tabela 1 - Sexo, idade, área de estudos e relação com a regulamentação relativa ao plágio por ciclo de estudos

\begin{tabular}{|c|c|c|c|c|c|}
\hline & & \multicolumn{3}{|c|}{ Ciclo de Estudos } & \multirow{2}{*}{ Total } \\
\hline & & $1^{\circ}$ Ciclo & $2^{\circ}$ Ciclo & $3^{\circ}$ Ciclo & \\
\hline \multirow{2}{*}{ Sexo $(\%)$} & Masculino & 37,2 & 32,2 & 43,9 & 35,9 \\
\hline & Feminino & 62,8 & 67,8 & 56,1 & 64,1 \\
\hline \multirow{2}{*}{ Idade (Anos) } & Média & 22,5 & 27,0 & 39,8 & 26,1 \\
\hline & Desvio P. & 7,0 & 7,6 & 8,6 & 9,0 \\
\hline \multirow{2}{*}{$\begin{array}{l}\text { Sabe se existe uma regulamentação } \\
\text { escrita para situações de plágio (\%) }\end{array}$} & Sim & 62,8 & 58,8 & 40,9 & 59,0 \\
\hline & Não & 37,2 & 41,2 & 59,1 & 41,0 \\
\hline \multirow{4}{*}{ Área de estudos (\%) } & Ciências Empresariais & 22,7 & 33,1 & 22,2 & 26,6 \\
\hline & Ciências Sociais & 60,7 & 41,5 & 65,1 & 53,9 \\
\hline & Tecnologia & 16,5 & 16,1 & 4,8 & 15,2 \\
\hline & Arquitetura & 0,0 & 9,3 & 7,9 & 4,4 \\
\hline Total (N) & & 328 & 255 & 66 & 649 \\
\hline
\end{tabular}

* Percentagens válidas (21 casos não classificados por ausência de informação).

Fonte: Elaboração própria.

Os estudantes inquiridos são predominantemente do sexo feminino (64,1 por cento), especialmente nos cursos de mestrado (67,8 por cento). Como seria expectável, a média etária aumenta progressivamente ao longo dos ciclos de ensino, de 22,5 anos entre alunos de primeiro ciclo eleva-se até aos 39,8 anos no caso do terceiro ciclo. Quando questionados se sabem que existe uma regulamentação escrita para situações de plágio na sua instituição de ensino, a maioria dos estudantes em licenciaturas (62,8 por cento) e mestrados (58,8 por cento) responde afirmativamente, mas só 40,9 por cento dos doutorandos o fazem. Não há dados que permitam esclarecer os motivos do conhecimento sobre a existência desses regulamentos diminuir ao longo dos ciclos de estudos; porém podemos colocar como hipótese que a maior ou menor ligação à instituição permita, pelo menos em parte, explicar esta situação, dado ser mais provável que os doutorandos tenham mais ligações a outras instituições de ensino ou profissionais do que os estudantes de mestrado e, especialmente, do que os de licenciatura, e possam, por isso mesmo, ter também menor conhecimento dos regulamentos que a regem. As áreas de estudo dos inquiridos refletem a oferta formativa da instituição em análise, predominando as ciências sociais e empresariais e assumindo menor peso as tecnologias e a arquitetura. 


\section{A incidência de plágio entre ciclos de estudos: o ponto de partida para a análise das percepções dos estudantes ao longo do percurso acadêmico}

Mais de 28 por cento dos estudantes inquiridos admitem que já cometeram plágio nos seus cursos. Todavia, ainda que as diferenças não sejam significativas, é interessante notar que a incidência de plágio é distinta entre ciclos: cerca de 31 por cento nas licenciaturas, 28 por cento nos mestrados e, aproximadamente, 17 por cento nos doutoramentos (Tabela 2).

Tabela 2 - Incidência de plágio por ciclo de estudos

\begin{tabular}{|c|c|c|c|c|c|}
\hline & & \multicolumn{3}{|c|}{ Ciclo de Estudos } & \multirow{2}{*}{ Tota } \\
\hline & & $1^{\circ}$ Ciclo & $2^{\circ}$ Ciclo & $3^{\circ}$ Ciclo & \\
\hline \multirow{2}{*}{ Alguma vez cometeu plágio? } & $\operatorname{Sim}(\%)$ & 31,4 & 27,8 & 16,7 & 28,5 \\
\hline & Não (\%) & 68,6 & 72,2 & 83,3 & 71,5 \\
\hline
\end{tabular}

Fonte: Elaboração própria.

Quanto à influência de fatores individuais nesta declaração, não foram encontradas diferenças estatisticamente significativas de acordo com o sexo ou a idade; já o conhecimento da política institucional gera diferenças significativas $[\chi 2(1)=4,718, p=0,035]$, sendo maior a percentagem dos que admitem ter cometido plágio entre os estudantes que não sabem que essa regulamentação existe (33,1 por cento) do que entre os que sabem (25,3 por cento). No que diz respeito ao contexto, a área de estudo introduz diferenças significativas $[\chi 2(3)=12,688, p=0,005]$, verificando-se que a percentagem de estudantes que admitiu ter cometido plágio nas tecnologias (42,1 por cento) e nas ciências empresariais (35,9 por cento) é acentuadamente maior do que entre os estudantes nas ciências sociais $(22,3$ por cento) e arquitetura (22,2 por cento).

Nos três estudos anteriormente referidos, a incidência de diversas formas de plágio no ensino superior português foi mensurada de formas distintas. No primeiro, considerando estudantes em diversos ciclos, áreas e instituições, essa incidência varia entre os 1,7 por cento ("comprar um ensaio/trabalho/artigo, seja na internet ou de alguém, e submeter como se fosse da sua autoria") e os 45,6 por cento ("reciclar ensaio/trabalho/artigo escrito para uma dada disciplina e usá-lo numa outra”), assinalando-se que as mulheres e os estudantes do terceiro ciclo são os menos inclinados a plagiar (TEIXEIRA, 2011, p. 11). No segundo, avalia-se a incidência de forma projetiva, tendo, por exemplo, 73 por cento dos alunos inquiridos de primeiro ciclo em várias áreas e instituições declarado que "apresentariam o mesmo trabalho em diferentes disciplinas", e 38,9 por cento que "copiariam um trabalho da internet” (ALMEIDA et al., 2015, p. 46), destacando-se diferenças por áreas 
de estudo - nomeadamente, a maior propensão dos estudantes de Medicina ao autoplágio (85 por cento) do que os de Ciências Sociais (62,8 por cento) ou Direito (54,3 por cento) (ALMEIDA et al., 2015), mas não sendo testadas outras variáveis de segmentação nesses resultados. Em contexto português, apenas a investigação de âmbito internacional recorreu a indicador de sintese - "acredita que já cometeu plágio de forma acidental ou deliberada" - e aferiu incidência de plágio de 39 por cento considerando conjuntamente alunos de primeiro e segundo ciclo em várias áreas e instituições de ensino (GLENDINNING, 2014, p. 2).

Esses valores de incidência ou propensão ao plágio são dificilmente compagináveis entre si, mas, colocados a par com o valor de síntese obtido nesta análise, revelam-se maioritariamente mais elevados. Porém, como foi antes assinalado, a leitura da incidência de plágio, particularmente quando aferida por meio de indicadores de síntese, não deve ignorar que os estudantes não têm igual concepção daquilo que configura plágio e, portanto, suas declarações sobre como ou quanto plagiam constituem, sobretudo, um ponto de partida para desvendar a previsível miríade de percepções que lhes subjazem.

\section{Percepções sobre plágio ao longo do percurso acadêmico: limites, gravidade, motivadores e dissuasores}

Ao escalpelizar o que os estudantes inquiridos entendem por plágio, assoma de imediato que, em termos globais, apenas o cenário relativo a plagiar palavra por palavra (C1) suscita essa classificação em quase todos os inquiridos (96,5 por cento). Com efeito, cerca de um quarto não considera plágio os cenários relativos à forma menos complexa de plágio mosaico - pois resulta de uma utilização abusiva de uma fonte não creditada - (C2; 73,7 por cento), à apropriação autorizada (C5; 72,1 por cento) e à compra (C6; 77 por cento) de trabalhos. Essa dissonância agravase no caso do autoplágio (C4) ou do plágio mosaico mais complexo - dado que a utilização abusiva surge acompanhada por referência correta à fonte utilizada (C3), entendidos como plágio por apenas, respectivamente, 48,7 e 24,5 por cento dos inquiridos (Tabela 3).

Esses resultados vão de encontro aos obtidos por Gama et al. (2013a, p. 630) e Almeida et al. (2015, p. 43), que testaram o plágio palavra por palavra - "copiar trabalho da internet" - e verificaram que foi considerado fraude por 81,6 por cento dos estudantes de licenciaturas em Economia e Administração, ou por 84,4 por cento considerando todas as áreas de estudos, parcelas que se reduzem, respectivamente, a 75,5 e 75,8 por cento no caso da apropriação autorizada - "emprestar a colegas trabalho realizado por si próprio para que estes apresentem como seu" - e a 63,7 e 62,7 por cento no caso do autoplágio - "apresentar o mesmo trabalho em diferentes disciplinas”. A compra de trabalhos foi testada, especificando-se que decorria entre colegas, tendo sido considerada fraude por 96,1 por cento dos inquiridos no primeiro caso e 95 por cento no segundo. 
Tabela 3 - Classificação de seis cenários enquanto plágio e avaliação da sua gravidade, total e por ciclo de estudos

\begin{tabular}{|c|c|c|c|c|c|}
\hline & & & 0 de Estu & & \\
\hline & & $1^{\circ}$ Ciclo & $2^{\circ}$ Ciclo & $3^{\circ}$ Ciclo & \\
\hline & Configura Plágio (\%) ${ }^{1}$ & 94,5 & 98,4 & 98,5 & 96,5 \\
\hline C1. Retirar excerto, texto ou imagem, de livro, artigo ou da & Gravidade (Média)² & 5,3 & 5,6 & 5,8 & 5,5 \\
\hline & Gravidade (Desvio P.) & 1,0 & 0,8 & 0,4 & 0,9 \\
\hline & Configura Plágio $(\%)^{3}$ & 67,1 & 76,9 & 93,9 & 73,7 \\
\hline C2. Retirar um excerto de um texto fazer pequenas & Gravidade (Média) $^{4}$ & 4,8 & 5,2 & 5,7 & 5,0 \\
\hline & Gravidade (Desvio P.) & 1,1 & 1,0 & 0,5 & 1,0 \\
\hline & Configura Plágio $(\%)^{5}$ & 20,4 & 26,3 & 37,9 & 24,5 \\
\hline mudando a ordem, fazendo a referência no texto (ex. Ramos, & Gravidade (Média) ${ }^{6}$ & 2,9 & 3,1 & 3,7 & 3,1 \\
\hline & Gravidade (Desvio P.) & 1,6 & 1,6 & 1,7 & 1,6 \\
\hline & Configura Plágio $(\%)^{7}$ & 43,9 & 51,0 & 63,6 & 48,7 \\
\hline C4. Utilizar dados, textos, ideias, conclusões de trabalhos & Gravidade (Média) ${ }^{8}$ & 3,6 & 4,0 & 4,1 & 3,8 \\
\hline & Gravidade (Desvio P.) & 1,7 & 1,7 & 1,6 & 1,7 \\
\hline & Configura Plágio (\%) & 72,3 & 72,2 & 71,2 & 72,1 \\
\hline C5. Utilizar um trabalho de um colega seu, já anteriormente & Gravidade (Média) & 4,8 & 4,8 & 4,8 & 4,8 \\
\hline & Gravidade (Desvio P.) & 1,3 & 1,3 & 1,6 & 1,3 \\
\hline & Configura Plágio (\%) & 77,7 & 76,1 & 77,3 & 77,0 \\
\hline C6. Comprar um trabalho a alguém e apresentá-Io como seu & Gravidade (Média) & 5,5 & 5,6 & 5,8 & 5,6 \\
\hline & Gravidade (Desvio P.) & 1,0 & 0,9 & 0,7 & 1,0 \\
\hline $\begin{array}{l}{ }^{1} \chi^{2}(2)=7,331, p=0,026 ;{ }^{2} F_{B F}(2,613,1)=23,854, p<0,001 ; 1 \\
{ }^{3} \chi^{2}(2)=22,668, p<0,001 ;{ }^{4} F_{B F}(2,602,7)=39,147, p<0,001 ; \\
{ }^{5} \chi^{2}(2)=9,763, p=0,008 ;{ }^{2} F(2,646)=6,482, p=0,002 ; 1^{0} \text { e } 2 \\
{ }^{7} \chi^{2}(2)=9,446, p=0,009 ;{ }^{8} F(2,646)=4,757, p=0,009 ; 1^{0} \text { cicl }\end{array}$ & $\begin{array}{l}\text { lo difere dos restantes } \\
\text { os os ciclos diferem er } \\
\text { los diferem do } 3^{\circ} \text {. } \\
\text { fere do } 2^{\circ} \text {. }\end{array}$ & ciclo d & & & \\
\hline
\end{tabular}

Nota: Apresentam-se apenas os resultados significativos. Recorreu-se ao teste $\mathrm{F}$ de Brown-Forsythe quando não se verificava o pressuposto da homogeneidade de variâncias.

Fonte: Elaboração própria.

Quanto à gravidade atribuída pelos estudantes inquiridos aos vários cenários, em termos globais, numa escala de seis pontos de 1 (totalmente aceitável) a 6 (totalmente inaceitável), a compra de trabalhos é, em termos médios, a prática considerada mais 
grave $(5,6)$, seguida depois pelo plágio palavra por palavra $(5,5)$, o plágio mosaico menos complexo $(5,0)$ e a apropriação autorizada $(4,8)$; com bem menor gravidade seguem-se 0 autoplágio $(3,8)$ e a forma mais complexa de plágio mosaico $(3,1)$.

A maior gravidade atribuída à compra de trabalhos pode ser explicada se considerarmos que, em Portugal, mas apenas considerando alunos de primeiro ciclo, Almeida et al. (2015, p. 44) destacam que, "para atribuir gravidade às práticas de fraude, os alunos parecem usar como critério, para além da instância de avaliação, e talvez acima dela, a acessibilidade à oportunidade de cometer fraude”, ou seja, o fato de que nem todos podem comprar um trabalho sobrepesa na avaliação da gravidade dessa forma de plágio, verificando-se por meio do caso em estudo que em todos os ciclos de estudo se aplica este filtro avaliativo sensível a desigualdades sociais.

Também os outros estudos referidos demonstraram que quanto maior a certeza de que uma prática constitui fraude, maior gravidade lhe é atribuída (GAMA et al., 2013a; ALMEIDA et al., 2015). Em Glendinning (2014, p. 11), o plágio palavra por palavra - "palavra por palavra sem aspas" - foi considerado como tal por 90 por cento dos alunos de primeiro e segundo ciclos em várias áreas e instituições, valor que se reduz a 60 por cento relativamente ao plágio mosaico mais simples - "algumas palavras alteradas sem aspas, citações nem referências" - e a 16 por cento no mais complexo - "algumas palavras alteradas sem aspas ou citações mas com referências". A gravidade dessas práticas foi averiguada questionando se mereciam punição e a parcela que aprova esse vaticínio eleva-se perante práticas mais facilmente identificáveis como plágio. A semelhança entre os resultados obtidos nessas diversas investigações indicia a existência de convergências quanto às percepções sobre o que constitui plágio entre alunos do ensino superior em Portugal, assim como no mecanismo a que recorrem para lhes atribuir determinado grau de gravidade.

Comparando, agora, as percepções dos estudantes inquiridos por ciclo de estudo, verificamos que estas parecem ganhar acuidade consoante o ciclo se eleva, ou seja, excetuando a apropriação autorizada e a compra de trabalhos, em que, sobretudo, se verifica uma grande estabilidade, nos quatro cenários restantes, entre o primeiro e o terceiro ciclo cresce paulatinamente a percentagem daqueles que os consideram plágio, assim como aumenta a gravidade que lhes atribuem. Acresce-se que a maioria dessas diferenças se reveste de significância estatística, o que contribui para reforçar o efeito positivo do ciclo de estudos na delimitação das várias formas de plagiar e na avaliação da sua gravidade.

Existem também diferenças estatisticamente significativas de acordo com os fatores individuais e contextuais em análise, acrescendo assim à falta de univocidade entre os estudantes nessas percepções (Tabela 4). Quanto aos primeiros, sobressai a relação com o fato de saberem que existem regulamentos institucionais relativos ao plágio, sendo aqueles que o sabem quem revela maior facilidade em identificar os cenários 2, 4, 5 e 6 como plágio do que aqueles que não o sabem. Já as alunas consideram plágio mais vezes os cenários 1 e 4, e atribuem maior gravidade do que os alunos ao primeiro. $\mathrm{E}$ os estudantes menos jovens têm maior facilidade de classificar os cenários relativos a plágio mosaico - 2 e 3- e atribuem-lhes maior gravidade do que os mais jovens. No que concerne ao fator contextual, os estudantes em ciências sociais destacam-se dos demais, quer porque mais frequentemente consideram os cenários 2, 4 e 5 como plágio, quer porque lhes atribuem maior gravidade. 
Tabela 4 - Resultados de testes de associação da classificação de seis cenários enquanto plágio e da avaliação da sua gravidade com fatores individuais e contextuais

\begin{tabular}{|c|c|c|c|c|c|c|c|c|c|c|c|c|c|c|c|c|c|}
\hline & & \multicolumn{3}{|c|}{ Sexo } & \multicolumn{4}{|c|}{ Idade } & \multicolumn{4}{|c|}{ Relação com o regulamento } & \multicolumn{5}{|c|}{ Área de estudos } \\
\hline & & M & $\mathrm{F}$ & Sig. & $17-19$ & $20-22 \vdots \vdots$ & 23 ou & & Sig. & $\begin{array}{l}\text { Sabe que } \\
\text { existe }\end{array}$ & $\begin{array}{l}\text { Não sabe } \\
\text { que existe }\end{array}$ & Sig. & $\begin{array}{c}\text { Ciências } \\
\text { Empresariais }\end{array}$ & $\begin{array}{l}\text { Ciências } \\
\text { Sociais }\end{array}$ & Tecnologias & Arquitetura & Sig. \\
\hline \multirow{2}{*}{$\begin{array}{l}\text { C1. Retirar excerto, texto ou imagem, } \\
\text { de livro, artigo ou da internet e integrá- } \\
\text { lo no trabalho como seu }\end{array}$} & $\begin{array}{l}\text { Configura Plágio } \\
\text { (Sim) }\end{array}$ & $93,7 \%$ & $98,1 \%$ & ** & & & & & & & & & $97,0 \%$ & $97,8 \%$ & $86,8 \%$ & $100,0 \%$ & ** \\
\hline & Gravidade (Média) & 3,6 & 3,9 & * & 5,2 & 5,3 & 5,7 & $* * \star$ & & & & & 5,4 & 5,6 & 5,0 & 5,5 & $\star * \star$ \\
\hline \multirow{2}{*}{$\begin{array}{l}\text { C2. Retirar um excerto de um texto, } \\
\text { fazer pequenas modificações de } \\
\text { linguagem e apresentá-lo como seu }\end{array}$} & $\begin{array}{l}\text { Configura Plágio } \\
\text { (Sim) }\end{array}$ & & & & $64,6 \%$ & $68,1 \%$ & $81,3 \%$ & 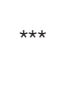 & $77,5 \%$ & & $3,8 \%$ & * & $63,5 \%$ & $83,5 \%$ & $52,6 \%$ & $66,7 \%$ & 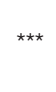 \\
\hline & Gravidade (Média) & & & & 4,7 & 4,9 & 5,3 & $* \star \star$ & & & & & 4,8 & 5,2 & 4,7 & 5,1 & ** \\
\hline \multirow{2}{*}{$\begin{array}{l}\text { C3. Usar grande parte do conteúdo de } \\
\text { um texto publicado mudando a ordem, } \\
\text { fazendo a referência no texto (ex. } \\
\text { Ramos, 2014) e aparecendo a fonte } \\
\text { original na bibliografia }\end{array}$} & $\begin{array}{l}\text { Configura Plágio } \\
\text { (Sim) }\end{array}$ & & & & $18,5 \%$ & $20,6 \%$ & $29,1 \%$ & * & & & & & & & & & \\
\hline & Gravidade (Média) & & & & 2,9 & 2,8 & 3,3 & ** & & & & & & & & & \\
\hline \multirow{2}{*}{$\begin{array}{l}\text { C4. Utilizar dados, textos, ideias, } \\
\text { conclusões de trabalhos anteriores } \\
\text { seus, sem fazer referência a eles }\end{array}$} & $\begin{array}{l}\text { Configura Plágio } \\
\qquad \text { (Sim) }\end{array}$ & $42,0 \%$ & $52,4 \%$ & * & & & & & $55,0 \%$ & &, $4 \%$ & $* \star *$ & $39,5 \%$ & $58,7 \%$ & $25,0 \%$ & $37,0 \%$ & $* \star *$ \\
\hline & Gravidade (Média) & & & & & & & & & & & & 3,5 & 4,1 & 3,1 & 4,0 & $* \star *$ \\
\hline \multirow{2}{*}{$\begin{array}{l}\text { C5. Utilizar um trabalho de um colega } \\
\text { seu, já anteriormente avaliado e com } \\
\text { autorização deste }\end{array}$} & $\begin{array}{l}\text { Configura Plágio } \\
\text { (Sim) }\end{array}$ & & & & & & & & $76,2 \%$ & & , $2 \%$ & $\star \star$ & $64,7 \%$ & $76,8 \%$ & $63,2 \%$ & $77,8 \%$ & * \\
\hline & Gravidade (Média) & & & & & & & & & & & & 4,5 & 5,0 & 4,5 & 5,3 & $* \star$ \\
\hline \multirow{2}{*}{$\begin{array}{l}\text { C6. Comprar um trabalho a alguém e } \\
\text { apresentá-lo como seu }\end{array}$} & $\begin{array}{l}\text { Configura Plágio } \\
\text { (Sim) }\end{array}$ & & & & & & & & $80,1 \%$ & & $3,2 \%$ & * & & & & & \\
\hline & Gravidade (Média) & & & & & & & & 5,7 & & 5,5 & * & 5,5 & 5,7 & 5,2 & 5,6 & * \\
\hline
\end{tabular}

\section{${ }^{* * *} p<0,001 \quad{ }^{* *} p<0,001{ }^{*} p<0,05$}

Nota: apresentam-se apenas os resultados estatisticamente significativos

Fonte: Elaboração própria. 
Essas ilações permitem aprofundar a reflexão que iniciamos antes sobre a incidência do plágio entre os inquiridos e a relatada por outros estudos. Desde logo, atesta-se a dificuldade de interpretar indicadores de sintese, pois neles se subsume uma miriade de interpretações sobre o que constitui plágio. Em segundo lugar, ao decantar essas diversas opiniões, sobressai que a forma de plágio mais grosseira - o plágio palavra por palavra - é a única que surge (quase) consensualmente considerada enquanto tal, existindo dúvidas assinaláveis sobre o julgamento de outros cenários de plágio, especialmente no que concerne ao autoplágio e ao plágio mosaico com referência às fontes (abusadas), tanto na população aqui analisada como noutras em território português. Assim, é provável que a parcela que admite ter plagiado aumentasse sobremaneira se conseguíssemos avaliar efetivamente as práticas dos estudantes, e não apenas o que estes declaram fazer. Em terceiro lugar, neste estudo, verificou-se que as percepções sobre o que constitui plágio se tornam mais precisas ao longo do percurso acadêmico, sendo, portanto, plausível colocar como hipótese que a incidência de plágio declarada por estudantes em licenciaturas (31,4 por cento) se revele mais subestimada do que sucede com os de mestrados (27,8 por cento) ou de doutoramentos (16,7 por cento), porventura o mesmo ocorrendo noutras populações estudantis. Por outro lado, também autoriza equacionar que, ao longo do processo de socialização acadêmica decorrente da progressão entre ciclos de ensino, esses estudantes efetivamente acedem aos conhecimentos sobre o plágio e às competências para a intertextualidade científica que lhes permite uma maior acuidade no confinamento dessa prática e, assim, também maior noção da sua gravidade e de como não o cometer por descuido ou incompetência em relação às normas em vigor. Trata-se de uma aproximação à cultura acadêmica que certamente beneficiará com a maior proximidade entre alunos e docentes, que geralmente se verifica nos cursos de mestrado e, sobretudo, nos de doutoramento, comparando-se aos de licenciatura; assim como de empreendimentos individuais dos próprios estudantes destinados a sistematizar e aprofundar autonomamente esses conhecimentos e competências durante seu percurso acadêmico.

Sobressai, portanto, a importância da formação no caso específico do plágio, porém, como também se verificou, nem todas as indecisões sobre as várias faces que esta prática pode assumir se dissipam entre os doutorandos em estudo, o que sugere que essa formação carece de maior destaque na sua socialização acadêmica e, porventura, de ser antecipada, procurando minimizar as maiores dificuldades reveladas pelos alunos de licenciatura e pelos mais jovens. Note-se ainda que as diferenças - estatisticamente significativas - entre as diversas áreas de estudo revelam igualmente a necessidade de dar transversalidade a essa formação para a honestidade acadêmica e científica. Não será despiciendo considerar que, se todos os estudantes não possuírem o conjunto de conhecimentos e competências que lhes permite evitar cometer plágio de forma não intencional, além da incidência dessa fraude ser previsivelmente maior, cometê-la, ou não, passaria a ser mais um indicador de desigualdades sociais entre estudantes do que dos seus princípios éticos e morais.

Os estudantes inquiridos foram também convidados a avaliar a importância que atribuem a dezenove fatores potenciais motivadores do plágio. A Tabela 5 permite visualizar os onze fatores que reuniram avaliações médias totais iguais ou superiores a quatro pontos, numa escala de 1 (nada importante) a 6 (muito importante), ordenadas de forma descendente. 
Destaque-se primeiro que, globalmente e em qualquer dos ciclos de ensino, a "preguiça ou inércia" surgem avaliadas como as mais importantes motivações para o plágio, em média, rondando os cinco valores na escala de seis pontos utilizada. Ou seja, atribui-se peso determinante às situações em que se comete plágio só porque seria mais trabalhoso evitá-lo, ou seja, a comportamentos fraudulentos e intencionais que refletem, sobretudo, ações moralmente questionáveis. Destacam-se também as "dificuldades na elaboração de um texto acadêmico", globalmente avaliadas como o segundo motivo mais importante para se cometer plágio $(4,5)$, uma avaliação que cresce de forma estatisticamente significativa entre estudantes de licenciatura, mestrado e doutoramento (respectivamente, 4,3, 4,7 e 5,0) até atingir, entre os últimos, um valor médio similar ao registado para a "preguiça ou inércia". Tal como de resto sucede com a "falta de domínio de uma linguagem escrita adequada ao ensino superior", pois, apesar da sua média geral ocupar apenas o sétimo lugar nessa hierarquia de fatores importantes $(4,1)$, aumenta significativamente entre ciclos (respectivamente, 3,8, 4,3 e 4,7), ocupando o terceiro lugar nas avaliações dos doutorandos. 0 fato dessas duas motivações relacionadas com (des)conhecimentos ganharem importância ao longo da carreira acadêmica sugere que esses alunos vão progressivamente decompondo as motivações para plagiar em não intencionais e intencionais, até lhes atribuírem um peso semelhante, uma reconfiguração a que também não será alheia a crescente consciência da pluralidade do plágio entre ciclos de estudos que se assinalou antes. A estes dois motivos acrescem outros dois, justamente "o fato de os alunos não terem noção do que é plagiar", que ocupa a quarta posição na hierarquia global $(4,2)$ e, ainda que não revele uma evolução linear entre ciclos, sua importância média afigura-se significativamente mais reduzida entre alunos de licenciatura do que para mestrandos e doutorandos e, também, "práticas pedagógicas de avaliação no âmbito do ensino secundário promovem a utilização de ideias/textos de outros sem a devida referência”, fator cuja importância geral é a menos elevada $(4,0)$, mas que cresce continuamente entre o primeiro e o terceiro ciclo de estudos de forma estatisticamente significativa.

As situações de plágio motivadas por dificuldades perante os currículos dos cursos ocupam também lugar de destaque nas avaliações médias globais, nomeadamente, a "falta de compreensão do que está a ser estudado" ocupa a terceira posição $(4,4)$ e a "falta de interesse na matéria”, a sexta $(4,1)$, avaliações que mantêm relativa estabilidade entre ciclos de estudos e sem diferenças estatisticamente significativas, perdendo assim lugares nessa hierarquia de importância ao longo dos ciclos de ensino. A "falta de tempo", que podemos também englobar nessa categoria ou encarar como indicativa do atual estilo de vida dos estudantes, apesar de se encontrar na quinta posição na avaliação global $(4,2)$, perde importância de forma significativa entre ciclos (respectivamente, 4,3, 4,0 e 3,8).

Essa lista de importantes motivadores do plágio, de acordo com os estudantes, completase com um conjunto de três fatores de âmbito distinto, mas com igual avaliação média global $(4,1)$ e importância crescente entre ciclos, nomeadamente "a ideia segundo a qual o importante é concluir as unidades curriculares, seja qual for o preço", que remete para questões éticas, "pensar que nunca será apanhado" refere-se ao processo de vigilância e "pensar que não é grave, porque todos o fazem”, à influência dos pares e neutralização dessa prática ou, em termos sociológicos, sua naturalização e reprodução nesse contexto acadêmico. 
Tabela 5 - Fatores motivadores de práticas de plágio, total e por ciclo de estudos

\begin{tabular}{|c|c|c|c|c|c|}
\hline & & \multicolumn{3}{|c|}{ Ciclo de Estudos } & \multirow{2}{*}{ Total } \\
\hline & & $1^{\circ}$ Ciclo & $2^{\circ}$ Ciclo & $3^{\circ}$ Ciclo & \\
\hline \multirow{2}{*}{ Preguiça/inércia } & Média & 4,9 & 4,9 & 5,1 & 4,9 \\
\hline & Desvio P. & 1,4 & 1,5 & 1,3 & 1,4 \\
\hline \multirow{2}{*}{ Dificuldades na elaboração de um texto acadêmico } & Média $^{1}$ & 4,3 & 4,7 & 5,0 & 4,5 \\
\hline & Desvio $\mathrm{P}$. & 1,4 & 1,4 & 1,2 & 1,4 \\
\hline \multirow{2}{*}{ Falta de compreensão do que está sendo estudado } & Média & 4,4 & 4,4 & 4,4 & 4,4 \\
\hline & Desvio $\mathrm{P}$. & 1,3 & 1,5 & 1,6 & 1,4 \\
\hline \multirow{2}{*}{0 fato de os alunos não terem noção do que é plagiar } & Média $^{2}$ & 4,0 & 4,4 & 4,2 & 4,2 \\
\hline & Desvio P. & 1,7 & 1,5 & 1,5 & 1,6 \\
\hline \multirow{2}{*}{ Falta de tempo } & Média $^{3}$ & 4,3 & 4,0 & 3,8 & 4,2 \\
\hline & Desvio P. & 1,4 & 1,6 & 1,8 & 1,5 \\
\hline \multirow{2}{*}{ Falta de interesse na matéria } & Média & 4,2 & 4,0 & 4,3 & 4,1 \\
\hline & Desvio P. & 1,3 & 1,6 & 1,6 & 1,5 \\
\hline \multirow{2}{*}{ Falta de domínio de uma linguagem escrita adequada ao ensino superior } & Média $^{4}$ & 3,8 & 4,3 & 4,7 & 4,1 \\
\hline & Desvio P. & 1,5 & 1,5 & 1,3 & 1,5 \\
\hline \multirow{2}{*}{$\begin{array}{l}\text { A ideia segundo a qual "o importante é concluir as unidades curriculares, } \\
\text { seja qual for o preço" }\end{array}$} & Média & 4,0 & 4,1 & 4,5 & 4,1 \\
\hline & Desvio P. & 1,6 & 1,7 & 1,5 & 1,6 \\
\hline \multirow{2}{*}{ Pensar que nunca será apanhado } & Média $^{5}$ & 3,9 & 4,2 & 4,6 & 4,1 \\
\hline & Desvio P. & 1,6 & 1,6 & 1,5 & 1,6 \\
\hline \multirow{2}{*}{ Pensar que não é grave, porque todos o fazem } & Média $^{6}$ & 4,0 & 4,1 & 4,5 & 4,1 \\
\hline & Desvio P. & 1,6 & 1,6 & 1,4 & 1,6 \\
\hline \multirow{2}{*}{$\begin{array}{l}\text { Práticas pedagógicas de avaliação no âmbito do ensino secundário } \\
\text { promovem a utilização de ideias/textos de outros sem a devida referência }\end{array}$} & Média $^{7}$ & 3,8 & 4,1 & 4,2 & 4,0 \\
\hline & Desvio P. & 1,7 & 1,6 & 1,6 & 1,7 \\
\hline
\end{tabular}

${ }^{1} F_{\mathrm{BF}}(2,346,5)=10,510, p<0,001 ; 1^{0}$ ciclo difere dos restantes.

${ }^{2} F_{\mathrm{BF}}(2,286,1)=4,067, p=0,018 ; 1^{\circ}$ ciclo difere do $2^{\circ}$ ciclo.

${ }^{3} F_{\mathrm{BE}}(2,207,2)=3,691, p=0,027 ; 1^{\circ}$ ciclo difere do $2^{\circ}$ ciclo.

${ }^{4} F_{\mathrm{BE}}(2,364,9)=16,237, p<0,001 ; 1^{\circ}$ ciclo difere dos restantes.

${ }^{5} F(2,646)=6,353, p=0,0021 ; 1^{\circ}$ ciclo difere dos restantes.

${ }^{6} F(2,646)=3,103, p=0,046 ; 1^{\circ}$ ciclo difere do $3^{\circ}$ ciclo.

${ }^{7} F(2,646)=3,192, p=0,042 ; 1^{\circ}$ ciclo difere do $2^{\circ}$ ciclo.

Nota: Apresentam-se apenas os resultados significativos. Recorreu-se ao teste $F$ de Brown-Forsythe quando não se verificava o pressuposto da homogeneidade de variâncias.

Fonte: Elaboração própria.

Os fatores individuais e contextuais em análise suscitam diferenças estatisticamente significativas apenas em algumas dessas avaliações, especialmente aquelas que reportam a motivações para plagiar devidas ao desconhecimento (Tabela 6). Veja-se que as alunas tendem a valorizar mais a "falta de tempo" enquanto motivador do plágio do que os alunos, mas também a falta de conhecimentos, seja por "não terem noção do que é plagiar" ou por "falta de linguagem adequada". 
Tabela 6 - Resultados de testes de associação da avaliação de importância de fatores motivadores de práticas de plágio com fatores individuais e contextuais

\begin{tabular}{|c|c|c|c|c|c|c|c|c|c|c|c|c|c|}
\hline & & \multicolumn{3}{|c|}{ Sexo } & \multicolumn{4}{|c|}{ Idade } & \multicolumn{5}{|c|}{ Área de estudos } \\
\hline & & M & $\mathrm{F}$ & Sig. & 17-19 & $20-22$ & 23 ou + & Sig. & $\begin{array}{c}\text { Ciências } \\
\text { Empresariais }\end{array}$ & $\begin{array}{l}\text { Ciências } \\
\text { Sociais }\end{array}$ & Tecnologias : & Arquitetura & Sig. \\
\hline Preguiça/inércia & Média & & & & & & & & 5,1 & 4,9 & 4,5 & 4,9 & * \\
\hline Dificuldades na elaboraçã̃o de um texto acadêmico & Média & & & & & & & & 4,4 & 4,7 & 4,0 & 4,7 & ** \\
\hline Falta de compreensão do que está sendo estudado & Média & & & & & & & & & & & & \\
\hline 0 fato de os alunos não terem noção do que é plagiar & Média & 4,0 & 4,3 & * & & & & & 4,0 & 4,3 & 4,0 & 4,7 & * \\
\hline Falta de tempo & Média & 4,0 & 4,3 & * & 4,5 & 4,3 & 3,9 & ** & 4,5 & 4,0 & 4,0 & 4,1 & * \\
\hline $\begin{array}{l}\text { Falta de domínio de uma linguagem escrita adequada ao ensino } \\
\text { superior }\end{array}$ & Média & 3,9 & 4,2 & * & 3,7 & 4,0 & 4,3 & $* * \star$ & 3,9 & 4,3 & 3,3 & 4,3 & $* * \star$ \\
\hline $\begin{array}{l}\text { A ideia segundo a qual "o importante é concluir as unidades } \\
\text { curriculares, seja qual for o preço" }\end{array}$ & Média & & & & 3,7 & 4,1 & 4,2 & ** & & & & & \\
\hline Pensar que nunca será apanhado & Média & & & & 3,7 & 4,1 & 4,2 & ** & & & & & \\
\hline Pensar que não é grave, porque todos o fazem & Média & & & & 3,8 & 4,1 & 4,3 & ** & & & & & \\
\hline
\end{tabular}

${ }^{* * *} p<0,001{ }^{* *} p<0,001{ }^{*} p<0,05$

Nota: apresentam-se apenas os resultados estatisticamente significativos.

Fonte: Elaboração própria. 
Já os menos jovens desvalorizam a "falta de tempo" relativamente aos mais jovens, mas valorizam a "falta de linguagem adequada" e as motivações relacionadas com a pouca vigilância e o sentimento de impunidade. 0 fato de saberem ou não que existem regulamentos sobre plágio não suscita diferenças significativas. A "preguiça/inércia" e a "falta de tempo" surgem sobrevalorizadas pelos estudantes em Ciências Empresariais, enquanto em Ciências Sociais e Arquitetura, justamente as duas áreas em que se verificou menor incidência de plágio reportado e, especialmente na primeira, também maior acerto na circunscrição das suas várias formas, sobrevalorizam-se as motivações relacionadas com "dificuldades na elaboração de um texto acadêmico", "o fato de os alunos não terem noção do que é plagiar" e também "falta de domínio de uma linguagem escrita adequada ao ensino superior".

Apenas uma investigação em Portugal procurou discernir o que os alunos julgam que motiva o plágio, ainda que recorrendo a uma forma de questionamento distinta: os estudantes de primeiro e segundo ciclo de várias proveniências institucionais e científicas eram convidados a escolher 10 de 22 fatores motivadores do plágio que consideravam importantes. As escolhas mais salientes foram de fatores relacionados com vigilância "acham que não vão ser apanhados" (72 por cento) -, ética - "é fácil copiar e colar da internet" (69 por cento) - e falta de tempo - "ficaram sem tempo" (69 por cento); seguindose depois dois fatores que remetem a desconhecimentos - "não percebem como citar e referir" (49 por cento) ou "não conseguem expressar ideias de outros autores em palavras próprias" (42 por cento) -; e outro relacionado com o currículo - "não conseguem gerir a carga de trabalho" (40 por cento), sendo os demais fatores escolhidos por percentagens mais reduzidas de alunos (GLENDINNING, 2014, p. 9).

Em suma, no caso dos estudantes observados nesta análise sobressaem cinco tipos de motivações para plagiar consideradas importantes ou muito importantes: comportamentos eticamente questionáveis, lacunas em conhecimentos, dificuldades com os currículos, vigilância pouco atenta e influência dos pares. No entanto a importância da segunda sobressai das demais, quer porque existe maior número de motivações que nela se inserem, quer porque suas avaliações médias são as que mais crescem entre ciclos de ensino, indiciando assim que, ao longo do percurso acadêmico, a referida progressiva tomada de consciência sobre a pluralidade do plágio se faz acompanhar de uma crescente constatação da sua complexidade e, portanto, do papel crucial que os conhecimentos desempenham para evitar situações de plágio, ainda que não intencionais. Constatações que se revelam mais evidentes entre alunas, estudantes menos jovens e os que cursam Ciências Sociais ou Arquitetura.

Se, num último exercício, colocarmos a par as percepções dos estudantes inquiridos com o conteúdo do seu código de conduta acadêmica que, acrescente-se, todos têm de declarar por honra conhecer logo no ato da matrícula, verifica-se que, se esse código fosse efetivamente conhecido por todos, certamente contribuiria para diminuir as hesitações em considerar fraudulentos os cenários apresentados neste estudo. Com efeito, as práticas de plágio, autoplágio e apropriação ou compra de trabalho encontram-se aí confinadas em termos comumente aceitos, todas são consideradas fraude acadêmica e passíveis de sanção, conforme o definido no regulamento disciplinar de discentes. Ademais, a 
defınição de plágio apresentada engloba a tipologia palavra por palavra e mosaico, ainda que não esclareça cabalmente que as situações de plágio também podem resultar da pouca proficiência na intertextualidade acadêmica, como da construção abusiva de paráfrases, da referenciação de uma citação direta como se de uma paráfrase se tratasse ou de uma incorreta utilização das normas de referenciação ${ }^{6}$.

Em termos de vigilância, esse código determina que apenas os elementos destinados à avaliação dos segundo e terceiro ciclos sejam obrigatoriamente submetidos a um programa de detecção de plágio, o que pode contribuir para a importância atribuída ao sentimento de impunidade enquanto motivador para plagiar, especialmente se considerarmos que a maioria dos estudantes nessa instituição está no primeiro ciclo.

\section{Notas conclusivas, limitações e prolongamentos}

Neste estudo sobressaem as várias faces do plágio entre estudantes em distintos ciclos do ensino superior. Com efeito, consoante avançam na hierarquia de graus acadêmicos, os estudantes declaram plagiar menos, revelam conhecimento mais aprofundado sobre o que constitui plágio e atribuem maior valor à posse desse conhecimento. Trata-se de um efeito positivo previsivelmente decorrente do seu próprio processo de socialização acadêmica, mas que, se comprova insuficiente para dirimir todas as hesitações em reconhecer os vários tipos de plágio, especialmente suas expressões mais complexas - o autoplágio e a compra ou apropriação de trabalhos. As insuficiências desse efeito assomam ainda se considerarmos que se afigura significativamente diferente consoante sexo, idade e área de formação dos estudantes, revelando que nem todos se beneficiam de igual forma do seu mergulho na cultura acadêmica, tanto no que concerne à valorização da honestidade acadêmica como no conhecimento sobre as normas em vigor e os desafios da escrita intertextual, aspectos fundamentais para produzir trabalhos isentos de plágio.

Dado que a transmissão desses conhecimentos e competências - e, aliás, quaisquer outras iniciativas de prevenção do plágio - se encontram ausentes do código de ética da instituição em estudo, será porventura necessário averiguar quais são as boas práticas pedagógicas ou individuais que contribuem para clarificar a percepção dos estudantes perante o plágio durante seu percurso acadêmico e consagrá-las nesse código ou nos currículos disciplinares, procurando assim universalizá-las, ainda que atendendo à pluralidade de percepções entre alunos. A regulamentação de medidas preventivas do plágio, mesmo que notoriamente difícil, pode se beneficiar da principal especificidade dessa prática em relação às demais fraudes acadêmicas, nomeadamente, a importância de possuir determinados conhecimentos e competências para evitá-lo, que, aliás, são também encarados como muito importantes pelos estudantes. Por outro lado, as hesitações perante as várias faces do plágio identificadas no caso em estudo, assim como a escassez de medidas institucionais que visam a prevenção desta fraude, foram também assinaladas noutros contextos portugueses e internacionais, o que demonstra que existem regularidades entre

\footnotetext{
6- Nesse código de conduta acadêmica, o plágio surge definido como "a utilização de uma obra, trabalho, palavras ou qualquer outro material publicado ou não publicado de outra ou outras pessoas e apresentá-la como se fosse sua, nomeadamente, copiar ou parafrasear sem claramente identificar a fonte" e o autoplágio como "a utilização de uma obra, trabalho, palavras ou qualquer outro material de autoria do próprio e apresentá-la de novo como se fosse original".
} 
estudantes e políticas institucionais que importa considerar em iniciativas destinadas a prevenir o plágio, em particular, e a fraude acadêmica em geral.

Convém salientar que os resultados obtidos não podem ser extrapolados para outras populações estudantis, pois, mesmo que existam caminhos analíticos e sentidos interpretativos comuns com estudos noutros contextos, as ilações aqui retiradas reportam unicamente aos alunos inquiridos neste estudo de caso. Assim como eventuais distorções populacionais resultantes do método de inquirição utilizado não autorizam um paralelismo total com o universo de estudantes no ano letivo de 2015/2016 na instituição observada.

Diríamos, para finalizar, que urge uniformizar instrumentos e indicadores que visem aferir percepções, mas também práticas relativas ao plágio acadêmico, facilitando assim a comparabilidade entre dados provenientes de vários contextos e alavancando a construção de um conhecimento cumulativo sobre essa temática. Em contexto português, esta área de estudos apenas se afirmou recentemente, carecendo também de análises qualitativas que permitam refinar e dar densidade às informações que têm sido recolhidas por métodos quantitativos, explorando, por exemplo, o que os estudantes efetivamente fazem, e não apenas o que dizem fazer, e como acederam aos conhecimentos que os ajudam a identificar e evitar o plágio, uma vez que já existe evidência farta de que são importantes e que os estudantes também os consideram como tal.

\section{Referēncias}

ADAM, Lee. Student perspectives on plagiarism. In: BRETAG, Tracey (ed.). Handbook of academic integrity. Singapura: Springer, 2016. p. 519-535.

ALMEIDA, Filipe et al. A fraude académica no ensino superior em Portugal. Coimbra: Universidade de Coimbra, 2015.

ALMEIDA, Filipe et al. Fraude e plágio na universidade: a urgência de uma cultura de integridade no ensino superior. Coimbra: Universidade de Coimbra, 2016.

BEASLEY, Eric. Students reported for cheating explain what they think would have stopped them. Ethics \& Behavior, Abingdon, v. 24, n. 3, p. 229-252, 2014.

BRETAG, Tracey; MAHMUD, Saadia. A model for determining student plagiarism: electronic detection and academic judgement. Journal of University Teaching \& Learning Practice,Wollongong, v. 6, n. 1, p. 49-60, 2009.

BRIMBLE, Mark. Why students cheat: an exploration of the motivators of student academic dishonesty in higher education. In: BRETAG, Tracey (ed.). Handbook of academic integrity. Singapura: Springer, 2016. p. 365-382.

CHILDERS, Dan; BRUTON, Sam. Should it be considered plagiarism? Student perceptions of complex citation issues. Journal of Academic Ethics, New York, v. 14, n. 1, p. 1-17, 2016. 
DIAS, Wagner; EISENBERG, Zena. Vozes diluídas no plágio: a (des)construção autoral entre alunos de licenciaturas. Pro-Posições, Campinas, v. 26, n. 1, p. 179-197, 2015.

ECKSTEIN, Max. Combating academic fraud: towards a culture of integrity. Paris: Unesco, 2003.

GAMA, Paulo et al. A ética dos alunos de administração e de economia no ensino superior. Revista de Administração Contemporânea, Curitiba, v. 17, n. 5, p. 620-641, 2013a.

GAMA, Paulo et al. Ethics and academic fraud among higher education engineering students in Portugal. In: INTERNATIONAL CONFERENCE OF THE PORTUGUESE SOCIETY FOR ENGINEERING EDUCATION, 1., 2013, Porto. Proceedings [...]. Lisboa: IEEE, 2013b. p. 1-7.

GLENDINNING, Irene. Responses to student plagiarism in higher education across Europe. International Journal for Educational Integrity, New York, v. 10, n. 1, p. 4-20, 2014.

GOTTARDELLO, Debora; PÀMIES, Maria; VALVERDE, Mireia. Professors' perceptions of university students' plagiarism: a literature review. Textos Universitaris de Biblioteconomia i Documentació, Barcelona, v. 39, p. 1-13, 2017.

GULLIFER, Judith; TYSON, Graham. Exploring university students' perceptions of plagiarism: a focus group study. Studies in Higher Education, Abingdon, v. 35, n. 4, p. 463-481, 2010.

HECKLER, Nina; FORDE, David. The role of cultural values in plagiarism in higher education. Journal of Academic Ethics, New York, v. 13, n. 1, p. 61-75, 2015.

HUSAIN, Fauzilah; SHAKER, Ghayth; MAHFOODH, Omer. Perceptions of and attitudes toward plagiarism and factors contributing to plagiarism: a review of studies. Journal of Academic Ethics, New York, v. 15, n. 2, p. 167-195, 2017.

HUTCHINGS, Catherine. Referencing and identity, voice and agency: adult learners' transformations within literacy practices. Higher Education Research \& Development, Abingdon, v. 32, n. 2, p. 312-324, 2014.

ISON, David. An empirical analysis of differences in plagiarism among world cultures. Journal of Higher Education Policy and Management, Abingdon, v. 40, n. 4, p. 291-304, 2018.

KAPOSI, David; DELL, Pippa. Discourses of plagiarism: moralist, proceduralist, developmental and intertextual approaches. British Journal of Sociology of Education, Abingdon, v. 33, n. 6, p. 813-830, 2012.

MACDONALD, Ranald; CARROLL, Jude. Plagiarism: a complex issue requiring a holistic institutional approach. Assessment \& Evaluation in Higher Education, Abingdon, v. 31, n. 2, p. 233-245, 2006.

MCCABE, Donald; TREVIÑO, Linda. Individual and contextual influences on academic dishonesty: a multicampus investigation. Research in Higher Education, New York, n. 38, p. 379-396, 1997. 
MCCABE, Donald; TREVIÑO, Linda; BUTTERFIELD, Kenneth. Honor codes and other contextual influences on academic integrity: a replication and extension to modified honor code settings. Research in Higher Education, New York, v. 43, n. 3, p. 357-378, 2002.

NEVILLE, Colin. The complete guide to referencing and avoiding plagiarism. New York: McGraw-Hill, 2010.

PARK, Chris. In other (people's) words: plagiarism by university students: literature and lessons. Assessment \& Evaluation in Higher Education, Abingdon, v. 5, n. 28, p. 471-488, 2003.

PEIXOTO, Paulo. A importância da universidade na promoção de uma cultura de honestidade. In: MARTINS, Ricardo; NASCIMENTO, Andreia (org.). 31 desafios para 0 ensino superior. Funchal: Universidade da Madeira, 2019. p. 75-79.

PEZUK, Julia et al. El uso de softwares para identificar plagio en textos académicos y educacionales. Educação e Pesquisa, São Paulo, v. 46, p. 1-22, 2020.

POWER, Lori. University students' perceptions of plagiarism. The Journal of Higher Education, Abingdon, v. 80, n. 6, p. 643-662, 2009.

RAZERA, Diana et al. Plagiarism awareness, perception, and attitudes among students and teachers in Swedish higher education: a case study. In: INTERNATIONAL PLAGIARISM CONFERENCE, 4., 2010, Newcastle. Proceedings [... ]. Newcastle: IPC, 2010. p. 21-23.

RETTINGER, David; KRAMER, Yair. Situational and personal causes of student cheating. Research in Higher Education, New York, v. 50, n. 3, p. 293-313, 2009.

RIOS, Terezinha Azerêdo. Ética na docência universitária: a caminho de uma universidade pedagógica? São Paulo: Universidade de São Paulo, 2009.

SUTHERLAND-SMITH, Wendy. Authorship, ownership and plagiarism in the digital age. In: BRETAG, Tracey (ed.). Handbook of academic integrity. Singapura: Springer, 2016. p. 575-589.

SUTHERLAND-SMITH, Wendy. Plagiarism, the Internet, and student learning: improving academic integrity. New York: Routledge, 2008.

TEIXEIRA, Aurora. Integridade académica em Portugal: relatório síntese global do estudo. Porto: FEP-UP: OBEGEF, 2011.

WALKER, John. Measuring plagiarism: researching what students do, not what they say they do. Studies in Higher Education, Abingdon, v. 35, n. 1, p. 41-59, 2010.

WOESSNER, Matthew. Beating the house: how inadequate penalties for cheating make plagiarism an excellent gamble. Political Science \& Politics, Cambridge, v. 37, n. 2, p. 313-320, 2004. 
Recebido em: 29.11.2019

Revisado em: 08.07.2020

Aprovado em: 04.08.2020

Madalena Ramos é licenciada em sociologia, mestre em sociologia e doutora em educação. É professora do Departamento de Métodos de Pesquisa Social do Instituto Universitário de Lisboa (ISCTE) e investigadora integrada no Centro de Investigação e Estudos de Sociologia (CIES-ISCTE).

César Morais é mestre em sociologia e doutorando em sociologia desde 2016 (bolsa da Fundação para a Ciência e Tecnologia, BD/115832/2016). É professor no Departamento de Sociologia da Faculdade de Ciências Sociais e Humanas da Universidade Nova de Lisboa (FCSH-UNL) e investigador no Centro Interdisciplinar de Ciências Sociais e Humanas da Universidade Nova de Lisboa (CICS.NOVA). 